\title{
"CRIANÇAS 'IMPOSSÍVEIS' - QUEM AS QUER, QUEM SE IMPORTA COM ELAS?"
}

\author{
Maria Vitória Campos Mamede Maia* \\ Maria Helena Rodrigues Navas Zamora\# \\ Junia de Vilhena" \\ Maria Inês Bittencourt ${ }^{\circledast 2}$
}

\begin{abstract}
RESUMO. Este artigo articula a prática clínica com a teoria winnicottiana sobre comportamento anti-social. Entendendo o ato anti-social como um pedido de socorro e implicitamente uma esperança de ser esse pedido atendido por quem o percebe, analisamos o caso de uma criança com queixa de agressividade extrema e falta de limites a partir desse prisma. Winnicott postula que a base da tendência anti-social resulta de uma experiência inicial boa que foi perdida e o aspecto essencial desta é a criança ter alcançado a capacidade de perceber que a causa do desastre foi devido à falha do ambiente. Cabe ao terapeuta, nesses casos, sobreviver às investidas da criança e reconstruir com ela ritmo, fidedignidade e confiança - sentimentos perdidos por ela ao longo desse processo de desapossamento.
\end{abstract}

Palavras-chave: atos anti-sociais, de-privação, Winnicott.

\section{"IMPOSSIBLE CHILDREN" - WHO WANTS THEM, WHO CARES?"}

\begin{abstract}
This article presents the clinical practice critically analyzed in the light of a winnicott's theory about antisocial behaviour.Accepting the child's antisocial behaviour as a request for help as well as a hope to be assisted by any one who notice it, this article analizes a case of an extremely agressive child who also had no limits in his relationships. Winnicott's theory postulates that the antisocial behaviour is the result of an early good experience which was lost; later on the child perceives that his agressiveness is due to the enviroment's fault by deprivating him of good experiences. The therapist must survive and re-establish the rythm and the child's lost feelings which resulted from that de-deprivation process.
\end{abstract}

Key words: Antisocial actions, de-privation, Winnicott.

\section{NIÑOS “IMPOSIBLES”-¿QUIÉN LOS QUIERE, QUIÉN SE IMPORTA CON ELLOS?}

RESUMEN. Este trabajo articula la práctica clínica a la teoría winnicottiana sobre comportamiento antisocial. Entendiendo el acto antisocial como un pedido de socorro e, implícitamente, una esperanza de que ese pedido sea atendido por quien lo percibe, analizamos el caso de un niño con queja de agresividad extrema y falta de límites a partir de ese prisma. Winnicott postula que la base de la tendencia antisocial resulta de una experiencia inicial buena que fue perdida y que el aspecto esencial de ésta es que el niño haya alcanzado la capacidad de percibir que lo del desastre se debió a la falla del ambiente. Cabe al terapeuta, en esos casos, sobrevivir a las investidas del niño y con él reconstruir ritmo, fidedignidad y confianza - sentimientos perdidos por él a lo largo de ese proceso de desposesión..

Palabras-clave: actos antisociales, deprivación, Winnicott..

* Psicóloga Clinica. Doutora em Psicologia Clínica. Psicopedagoga Clínica Ceperj-Uniceub. Pesquisadora do Laboratório Interdisciplinar de Pesquisa e Intervenção Social -LIPIS da Pontifícia Universidade Católica-PUC-Rio.

\# Doutora em Psicolgia Clínica. Professora do Departamento de Psicologia Clínica da PUC-Rio; Vice Coordenadora do Laboratório Interdisciplinar de Pesquisa e Intervenção Social -LIPIS da PUC-Rio.

II Doutora em Psicologia Clínica. Professora do Programa de Pós-Graduação em Psicologia da PUC-Rio. Pesquisadora da Associação Universitária de Pesquisa em Psicopatologia Fundamental.

x Psicanalista. Doutora em Psicologia Clínica. Professora Assistente do Departamento de Psicologia da PUC-Rio. Pesquisadora do Laboratório Interdisciplinar de Pesquisa e Intervenção Social -LIPIS da PUC-Rio 
Falar da agressividade da infância, de crianças cada vez menores que assustam e incomodam, é falar de algo estranhamente próximo a nós e violento, mas também colocado como muito distante de nossas vidas. Quem são essas crianças denominadas de anti-sociais? Afinal, quem se importa com elas?

O momento atual parece agudizar a dialética entre a identidade e alteridade, conduzindo-a a um paroxismo (Pelbart, 2003). O encontro com o Outro não é mais uma possibilidade de deixar-se afetar e de permitir-se novas interações, mas uma ameaça em potencial. Nos fundamentalismos cotidianos inventa-se e recria-se o perigo e o inimigo - bandido, favelado, traficante, terrorista, "menor" - para que se possa oferecer segurança e defesa. Todas as versões do "menor" assustam. Adivinha-se nesse tipo de ser, tão jovem quanto ameaçador, a perversidade precoce, a frieza com que planeja seus crimes, a falta de arrependimento de seus atos, a crueldade, enfim, todos os elementos que compõem o estereótipo do "irrecuperável", do mau de nascença.

A distinção entre menor e criança é fácil de entender. Criança é meu filho, é o filho dos amigos, são os irmãos, os sobrinhos, as crianças queridas por nós, as parecidas conosco. Menor é o ser temível que está nas ruas, atacando os moradores, perigosos até quando estão tontos de thiner. São os predadores, os assaltantes, os bandidos-mirins da FEBEM, os cheiradores de cola, os traficantes do morro, as pequenas prostitutas. Todos sabem o que quer dizer menor - ou será que algum de nós convida os menores do condomínio para o aniversário do filho? Menor é o Outro assustador dentro da criança e na criança, estragando a imagem de inocência, pureza e virtude com que ainda a pintam; a imagem utilizada para vender produtos e cativar os corações consumistas.

Evitamos o Outro, porque ele é irredutível em trazer sua dissimetria, sua diferença. Ele mostra que não formamos um todo harmônico, uma totalidade. $\mathrm{O}$ inaudito, o disruptivo, não pode ser esconjurado pela vida pacificada e nem tampouco poderá ser duradoura uma paz que não pode ser conseguida senão ignorando ou abafando gritos. Sempre haverá crianças que gritam, brigam e quebram a louça. Daí entende-se que ninguém quer essas crianças dissonantes, esses "capetas em forma de guris".

Segundo Maia (2007), Winnicott (1987) se dedicou, entre muitas coisas, a estudar as crianças antisociais. Ele postula que os comportamentos anti-sociais acontecem até nos bons lares e que tudo aquilo que leva um adolescente ou um adulto a um julgamento ou a uma prisão, teve início numa perda de algo que essas pessoas registram como sendo algo que antes possuíam e que lhes foi retirado. A base da tendência anti-social resulta de uma experiência inicial boa que foi perdida e o aspecto essencial desta é a criança ter alcançado a capacidade de perceber que a causa do desastre foi devida a uma falha do ambiente. Isso provoca a distorção da personalidade e o impulso de buscar a cura numa nova provisão ambiental. A esse processo de desapossamento, Winnicott (1987) denominará deprivação, e marcará a diferença entre essa situação e a de privação, ou seja, uma situação na qual a criança nunca teve nada, e por isso não perde coisa alguma mais tarde, diferente da situação das crianças que estamos chamando de anti-sociais.

Winnicott (1961, p. 241) nos fala que a maioria das pessoas pode dizer de seus pais: "eles cometeram erros, frustaram-nos constantemente e coube a eles apresentarem-nos ao Princípio de Realidade, arquiinimigo da espontaneidade, criatividade e do sentido de Real; mas eles realmente nunca nos abandonaram". O abandono, não sofrido pela maioria das pessoas, constitui a base da tendência anti-social. A criança perde de vista o objeto e passa a buscá-lo no meio que a deixou só e triste. Exatamente porque sofre e se entristece, exatamente porque possui em si o ressentimento e uma justificada reclamação em relação ao meio que a insultou e quase é capaz de recordar-se desse insulto, que Winnicott afirmará que essa criança ainda possui em si uma esperança.

\section{UMA CRIANÇA 'IMPOSSÍVEL' - RELATO DE UM CASO CLÍNICO}

Para nós é impensável falarmos de teoria sem uma prática. $\mathrm{O}$ humano se constitui em uma prática que se chama vida, e a teoria que tenta dar conta dessa vida, ou das fraturas dessa vida, não existe sem esse referencial. Falaremos de uma criança que teve, um dia, família, cuidado e carinho. Mas igualmente um dia, de repente, tudo isso se perdeu. Falaremos da teoria da tendência anti-social, entremeando-a com uma história de vida de uma criança que pudemos acompanhar por quase três anos. Luis ${ }^{1}$ trará para quem nos lê parte desta vida que se perde, mas que pode ser reencontrada e re-significada quando, no meio do caminho, ou do seu caminho, há pessoas que se importam com o sofrimento humano.

Luis tinha nove anos quando o conhecemos, mas parecia ter sete. Magro, rouco, mal se escutava sua

Todos os nomes foram trocados, bem como alguns detalhes que poderiam identificar a criança. A publicação do caso foi examinada e consentida pela Comissão de Ética do Departamento de Psicologia da PUC-Rio. 
voz, quase um sussurro. Menino quase raquítico, com roupas largas, sujas e velhas, trouxe à sua psicóloga a imagem do Dunga, o menor e mais desajeitado dos anões da Branca de Neve.

A história de vida de Luis é um testemunho do quanto a sua integridade psíquica poderia estar comprometida, pois pelas circunstâncias pelas quais ele já vivenciara, até mesmo sua presença viva poderia ser posta em dúvida. Órfão de mãe, filho não desejado, fruto de um caso do pai, espancado desde antes de nascer na barriga da mãe, aceito de favor na casa da tia paterna quando do falecimento de sua mãe, tendo um pai alcoólatra, violento e omisso, Luis atuava seu abandono com constantes fugas de casa e crises de agressividade. A família o colocou interno em um colégio público e nos fins de semana ele era entregue a um homem "bom", que cuidava dele e de um filho adotivo um pouco mais velho que Luis. Havia suspeita de abuso sexual, mas nada pôde ser provado, ou não se queria provar, ou não se queria saber. Em suas crises de agressividade ele era trancado em uma sala ou jogado num chuveiro frio para se acalmar. Mesmo assim era visto como um aluno dedicado, com boas notas. Adorava jogar futebol e gostava de jogar nas sessões que freqüentava no CIAP da PUC-Rio ${ }^{2}$. Interessante notar que Luis jamais agrediu a psicóloga que o atendia. Sempre colocou um objeto entre eles, como se avisasse que poderia se desorganizar se esse limite fosse ultrapassado. Quando visto pela psiquiatra do atendimento social do CIAP, a pedido de sua psicóloga, devido a essas sucessivas crises de agressividade, Luis relatou que estava com medo do colégio e do homem "bom". Quando perguntado se poderia falar por que motivo tinha medo, Luis respondeu que nada poderia falar. A psiquiatra perguntou se ele falaria para a psicóloga o motivo. Ele respondeu que não, porque ela era muito boa e que ele não queria machucá-la nem perdê-la. Luis não queria ser abandonado mais uma vez.

Acreditamos que possamos entender o comportamento anti-social como um modo de operar em um ambiente que não está sendo suficientemente bom para a criança. Em nossa opinião, o comportamento anti-social pode ser visto como uma estratégia de sobrevivência possível da criança em um ambiente privador. Luis se encontrava há muito em um ambiente privador e invasivo para sua integridade. Esse medo de ser abandonado era percebido na sua

2 O Centro de Investigação e Atendimento Psicológico (CIAP), vinculado ao Departamento de Psicologia da Pontifícia Universidade Católica do Rio de Janeiro, foi criado em 1994 e presta serviços à população, constituindo-se como campo de investigação clínica e de produção e divulgação de conhecimento. dificuldade de expressar afeto. Luis não olhava diretamente nos olhos de sua psicóloga, não sorria. As sessões iniciais foram marcadas por um único jogo, o jogo de damas. Não gostava de desenhar, se recusava a chegar perto das caixinhas de tinta, jamais se interessou ou reparou que havia, na sala de atendimento, uma casa de bonecas. Sempre era o mesmo ritual: chegava atrasado, e muito; sua tia o esquecia no colégio - não vinha porque tinha outro sobrinho para olhar; o pai, no início, o trazia, mas depois foi deixando de aparecer da mesma forma. Por um ano lidamos com faltas mais do que presenças, o mesmo jogo de damas e respostas sussurradas entre "não sei", "não me lembro", quando ousávamos perguntar algo do dia-a-dia de Luís. Luis respondia a qualquer pergunta com silêncio ou com o balançar de cabeça.

A tendência anti-social não seria, segundo Winnicott (1987), uma defesa organizada, e sim uma patologia da transicionalidade. O que acontece é que a mãe falha e não volta ao padrão anterior de "benignidade", e, como não volta, há o esvaecimento de sua lembrança, assim como há o esvaecimento do objeto transicional quando este perde seu vínculo com a mãe pelo abandono desta. Falhou uma mãe que deveria ser suficientemente boa, mas lembremos que, se Winnicott diz que não existe bebê sem sua mãe, também a mãe suficientemente boa não existe sem os outros. Como diz Safra (2002), ela não existe sem um campo sociocultural, que lhe possibilite exercer suas funções. Portanto, a boa maternagem, assim como suas falhas, têm origem na mãe, no pai, nos ancestrais, na situação social da mãe, nas características da sua cultura e de sua época. É um fenômeno complexo, pois cada gesto materno presentifica a memória do que é o cuidado materno em determinado grupo cultural. Winnicott afirma que por trás do desajustamento da criança está sempre um fracasso do ambiente em ajustar-se às necessidades da criança numa época de relativa dependência: "Depois, pode-se acrescentar um fracasso da família em curar os efeitos dessas deficiências; e poder-se-á ainda acrescentar o fracasso da sociedade, quando esta toma o lugar da família" (Winnicott, 1963a, p.252). É neste cenário de falhas sobre falhas que a criança se constitui: ou seja, como pode.

A repetição do jogo e a escolha sempre de jogos com regras estritas davam a Luis uma medida de segurança. Ele conhecia as regras de antemão, mesmo que na sua vida ele não pudesse dizer o mesmo. Não seria surpreendido por elas, mesmo que sempre tivesse sido surpreendido pelas mudanças das regras da vida e 
do mundo depois da morte de sua mãe ou até antes disso; mesmo que tivesse desenvolvido outras formas de lidar com esse mundo, onde ele aprendeu depressa demais a viver.

A psiquiatra relatou à psicóloga de Luis a confirmação sobre a suspeita de abuso, que fora anteriormente levantada a partir da fala do pai e da tia, nas poucas vezes em que, no corredor, falaram com ela. Em seguida, na sessão com Luis, ela se ajoelhou ao seu lado e disse-lhe: "Luis, a Doutora me contou sobre esse "homem bom". Eu quero te dizer que você não está sozinho, que eu não vou deixar nada acontecer com você. Mas você precisa confiar em mim e nela". Nesse dia Luis falou, entre sussurros, o que o fazia sofrer muito: falou sobre esse homem, sobre o colégio, o medo que ele tinha de ser machucado e principalmente do medo que ele tinha de não ter mais colégio para onde ir ou ficar. Entramos com uma denúncia no Juizado, procuramos a diretora do colégio, acompanhamos de perto todo o processo. Luis se sentiu amparado. Passou a sorrir um pouco, principalmente quando ganhava no jogo de damas. Talvez ele estivesse começando a ganhar no jogo da sua vida: alguém o ouvira e estava brigando por ele e apostando nele.

$\mathrm{O}$ olhar que a teoria winnicottiana lança para a tendência anti-social é de desapossamento, não uma simples carência. $\mathrm{O}$ descaso e o desamparo marcavam a vida desse menino. Tivemos de intervir energicamente muitas vezes com a tia de Luis. Certa vez, esta tia não o esperou na sala de espera. Luis olhou para sua psicóloga e perguntou: "Onde está ela?" Ela se abaixou para ficar perto de seus olhos, e disselhe: "Deve ter ido ao banheiro, ido dar uma volta, ela volta". Esperam. Ela não apareceu. Luis não tinha dinheiro para pegar o ônibus. Ele lhe garantiu que daria um jeito. Ela disse-lhe que não. Que ela tinha dois reais e que daria a ele e que o colocaria no ônibus. Luis acompanhou-a até o ponto de ônibus quieto, assustado. Esperaram o ônibus e, quando ele entrou, olhou para ela e sorriu. Foi a primeira vez que apareceu um sorriso nesse rosto sem ser por ter ganhado um jogo de damas. $\mathrm{O}$ sorriso de Luis, nesse dia, indicou-nos que algo começara a fazer sentido para ele, uma referência de cuidado em relação à criança que ele era, mas que não podia ser. Como Dunga, ele ganhara o olhar de alguém que não era de recriminação ou de esquecimento.

O pior da vida Luis já sabe. Talvez ele saiba de um jeito que nós não sabemos, porque fomos poupados: que as mães duram pouco, que os pais nem sempre querem os filhos, que os "homens bons" de bons não têm nada, que o mundo não tem lugar para todas crianças. Luis sabe que brincar não consola mais porque, em vez da alegria de estar escondido, só se tem o desastre de não ser encontrado. Para esse menino, talvez seja melhor não chorar. Não adianta. Não vem ninguém.

Ao longo do primeiro ano de atendimento, o ritual de levá-lo até o ponto de ônibus se repetiu. Do andar ao lado da psicóloga, Luis passou a permitir que lhe desse a mão; depois passou a querer dar a mão a ela para irem até o ponto; depois passou a esperar que ela o levasse até o ponto como algo certo e sem falha. De dentro do ônibus, um aceno de mão, como um "tchau", e um sorriso eram a resposta dele à sua psicóloga. Com o passar do atendimento, Luis permitiu que ela lhe desse um abraço antes de deixá-lo no ponto de ônibus e seu sorriso já aparecia com frequiência em seu rosto como resposta a esse contato afetivo junto com um "tchau", falado bem alto. Antes de entrar no ônibus Luis invariavelmente olhava para trás para ver se sua psicóloga continuava no ponto, esperando a partida.

Acabou o ano. No ano seguinte, Luis iria se formar na quarta série. Esse ano foi um ano de mais lutas. Um dia Luis chegou suado, cansado e muito atrasado. Sua psicóloga lhe perguntou o que houvera e onde estaria sua tia. Ele disse, "não adianta, ela foi buscar um livro em casa e não voltou. Eu não quero mais perder de chegar aqui. Pulei o muro e vim correndo". Foi dito a ele que isso era perigoso, ele respondeu que sempre soubera se virar. Ligamos para o colégio diversas vezes e combinamos com a mãe social que ela o colocaria no ônibus e que a psicóloga continuaria a fazer o que já fazia desde o ano anterior, colocaria Luis no ônibus de volta. Não mais vimos a tia e Luis passou a faltar pouco às sessões.

Do jogo de damas, Luis passou a brincar de dominó, aceitou brincar de mico dourado, memória e pega varetas. Um dia quebrou as regras que ele tanto prezava, inventou uma para que não perdesse. Conforme jogávamos, sua psicóloga conversava com ele, falava para ele e por ele muitas vezes. Luis agora já respondia, já tinha voz normal, a rouquidão desaparecera. Em uma sessão, onde era jogado o jogo de damas, Luis contou que brigou no colégio, e feio. Sua psicóloga perguntou-lhe o que acontecera. Ele relatou que, jogando futebol, um garoto subiu na rede do gol e ele avisou que não podia fazer isso - ele mesmo já havia ficado de castigo e levado advertência por fazer a mesma coisa - só que o garoto não saiu. Ele o puxou pela perna; o garoto revidou e xingou sua mãe. Luis não conseguiu se segurar e surrou o menino. Nesse momento do seu relato, sua psicóloga pegou suas mãos e disse-lhe: "Luis, sua mãe está morta... se 
não fosse você a defender a memória dela, quem faria isso?" Luis, pela primeira vez, demonstrou emoção extrema e seus olhos se encheram de água. Não chorou, mas ficou perto disso. Sua psicóloga perguntou, então, qual era o nome de sua mãe, e perplexa ouviu o nome dela, o nome de todos os meio-irmãos que ele possui, nomes que davam a ele uma família, pessoas que poderiam, talvez, estar a olhá-lo. Então ele não estaria em um colégio interno ou nas ruas de uma favela. Foi feita uma árvore-esquema de sua família para se poder entender quem era quem nisso tudo. Surgia no ar uma saída para Luis. A psicóloga procuraria essas pessoas e veria se alguém poderia cuidá-lo, porque no fim do ano ele não mais poderia ficar interno. Nas demais sessões, apareceram uma mãe que o levava à creche, uma irmã que o olhava até a mãe morrer; surgiu um retrato dele bebê que ele achava ter em algum lugar guardado, o resto estaria com outra irmã, que ele não via tinha muito tempo, mesmo que soubesse onde morava. "Até os seis anos eu tive casa, hoje ela não mais está lá, foi destruída porque tiraram as casas de cima do túnel". Quanto mais teríamos ainda de esperar para saber o quanto esse menino, que se virava sozinho quase sempre, perdera? Quantas vezes mais teríamos de ligar para o colégio, para o juiz, para o Conselho Tutelar, para o orelhão da favela para saber se Luis estava bem, se não teria se machucado, não teria brigado e estaria preso no quarto para se acalmar ou não estaria solto pelas vielas da favela?

A descrição que Winnicott (1963b, p.97) faz dessa criança que fica difícil é interessante pela gradação que ele constrói, num paradoxo que desfaz a hipérbole construída para ela. Essa criança é uma criança "carente, que afora isso é desgraçada, desesperada e inofensiva". No afixo - des - que sonoramente liga desgraçada a desesperada marca-se a deprivação, já que para essa criança seu mundo perdeu a graça e com isso adveio o desespero que a leva a atuar no meio. Mas, ao invés de marcar essa passagem ao ato como algo temeroso ao ambiente, Winnicott marca esse meio deprivador como a causa desse ciclo de perdas e dores, ao caracterizar essa criança como inofensiva: ofensivo foi o meio ambiente que falhou com ela. Sabendo disso, essa criança busca o que lhe falta, e nessa busca retrata-se a esperança de ser achada pelo meio mais uma vez e assim "superar um vazio", que "se origina de uma dissolução de continuidade da provisão ambiental".

Passamos o segundo ano de atendimento nos preparando para a formatura de Luis na quarta série. Ele pedira um bolo de chocolate. Sua psicóloga perguntou-lhe por quê. Ele disse: "Nunca tive um bolo só meu, nem uma festa de aniversário minha. Quero um bolo com o meu nome escrito, dá?". Ao longo de uma sessão de jogo de palitos, Luis disse: "Ganharei quatro convites para a formatura, poderia convidar minha tia, mas ela não vai; meu pai, mas esse...!!!; minha mãe... ela é morta; o primeiro então é seu, você vai, não vai?". Sua psicóloga disse-lhe que iria à formatura e que levaria o bolo. Luis pediu que no bolo tivesse o nome dele. Foi prometido que assim seria. Ele sorriu. Passamos a saber, através dele, das notas, das brigas, dos problemas, dos medos. Luis agora falava bastante, não havia mais nenhum resquício de rouquidão. Ele contou que trabalhava nos fins de semana para ganhar dinheiro num supermercado carregando "carro de madame". Com esse dinheiro comprara um relógio, camiseta e balas.

Chegou o final do ano e sua psicóloga foi à formatura. Luis, vendo-a entrar com o bolo e seu nome escrito nele e com refrigerantes, diz: "Viram? Eu tenho um bolo só meu! Eu não disse?" Ele ria, não sorria somente... Ele procurou o lugar para ela nas mesas reservadas para os convidados, não havia. Procuraram a diretora e ela falou, em voz baixa, que o colégio não esperava que alguém viesse à formatura de Luis. Sua psicóloga respondeu à diretora que de certo ela se enganara e disse a Luis: "Tenho certeza que eles colocaram os nomes nas mesas, mas sem ser em ordem alfabética. Acharemos seu nome, Luis. Deve estar do outro lado da quadra".Quando voltaram para procurar o nome de Luis em alguma outra mesa, encontraram, junto com outra família, o nome dele: assim havia, agora, um lugar para ela sentar-se e assistir sua formatura. Já tendo iniciado a festa de formatura, chegou uma irmã de Luis por parte de pai, Silvia. O lugar foi dado a ela. Silvia diz à psicóloga que outra irmã, Flávia, ficaria com Luis a partir de agora e que cuidaria dele. Flávia ficou sabendo o que ocorrera com Luis e como ele estava vivendo através da tia dele, madrinha de Flávia. Ela perdera, há muito, o contato com ele, mas agora seria diferente, ele moraria com ela.

Durante a formatura inteira a psicóloga de Luis fica sentada de frente para a turma dele, pois fora recolocada perto da banda dos bombeiros, que tocava para alegrar a festa. Quando ele recebeu o diploma mostrou-o de longe. Depois quis tirar retrato. Estava com roupa nova, tênis novo e extremamente feliz. Quando terminou a chamada da turma dele, ele veio até sua psicóloga e lhe entregou uma rosa. Para toda criança era dada uma rosa para entregar à mãe: ele a entregou a ela. Ela lhe deu um abraço apertado; ele retribuiu pela primeira vez em igual intensidade. 
Disse-lhe: "Conseguimos, né?". Ela se levantou e saiu. Realmente haviam conseguido.

A lição que as crianças anti-sociais têm de aprender é que existe uma fantasia de destruição que é diferente da realidade: mesmo ficando muito agressivas, o meio continua lá, intacto, sobrevive aos ataques delas. Luis aprendeu que mesmo destruindo, mesmo brigando, mesmo fugindo de casa e do colégio, mesmo faltando às sessões, as pessoas com quem ele poderia contar continuariam a esperá-lo. Assim, ele pôde confiar um pouco mais no mundo e, conseqüentemente, nele mesmo. Pode falar de sua mãe, pode falar de sua família, pode falar da creche para a qual ele ia levado por essa irmã e falar desta outra, que ele pouco conhecia, mas que hoje pretendia ficar com ele em casa. "Terei um armário e uma cama... isso é bom". Mais do que um armário e uma cama, Luis teria uma referência de lugar e de carinho. Um lugar que não tirariam dele por algum tempo, esperávamos.

\section{CONSIDERAÇÕES FINAIS}

Winnicott (1987) enfatiza-nos que mesmo que essas crianças consigam re-viver o momento de desapossamento, para a criança anti-social fica sempre um resto com o qual ela terá de lidar ao longo de sua vida. Pode-se "curar" a tendência anti-social através de um meio amoroso e firme, mas acreditamos que essas crianças sempre terão em si esse sofrimento registrado em seu psiquismo. Elas sabem que sobreviveram às adversidades da vida a elas impostas, mas não esquecem. Como nos fala o próprio Winnicott, são crianças que estão feridas, à procura de cuidados, e elas sabem que se forem cuidadas, sobreviverão. Serem "capetas em forma de guri" é a certeza de que essas crianças estão a juntar pedaços de vida; que um dia elas esperam ser abraçados por alguém que as ouça, em algum momento, de alguma forma. E assim esses atos, que cobrem hiatos entre o que se perdeu e o que se busca, deixarão de ser necessários.

Hoje Luis é uma criança que tem uma casa, tem uma irmã que cuida dele, que tenta se habituar aos descompassos que a vida marcou em Luis. Ele ri, brinca, ainda briga muito, muitas vezes ainda agride, mas, antes de tudo, tem esperanças de ir em frente. $\mathrm{O}$ único medo de Luis é que a irmã se canse dele e o mande embora. Neste novo ano, o terceiro de atendimento, ano de início difícil em adaptação com a irmã, Luis chorou quando ela lhe disse que talvez não agüentasse ficar com ele. Ele falou: "Sou um péssimo menino". Sua psicóloga lhe perguntou o que ele entendia por ser um péssimo menino. Ele listou tudo de errado que fazia, mas reiterou que tenta, muitas vezes, não fazer isso, como mentir, quebrar, destruir. Foi, então, perguntado a ele: E o que você tem de bom menino? Ele nada respondeu. Não havia para ele nenhuma qualidade a ser listada. Nesse momento, sua psicóloga lhe afirmou: "Não, Luis, eu discordo de você e de sua irmã, você não é um péssimo menino. Você poderia ter se transformado em um, você sabe, não? Você poderia ter ido para o tráfico, você poderia ter roubado, matado, como muitos colegas que você conheceu, não?"3 Luis balançou a cabeça mais uma vez, em uma mudez difícil de ser sustentada - o mais desamparado dos anões, o Dunga, se materializava de novo, como no primeiro ano de atendimento. Ela continuou a falar para ele e para a irmã: "Luis, eu te garanto, e afirmo para sua irmã, que isso você não é. $O$ que você me disse quando soube que iria morar com sua irmã?" Mais silêncio como resposta. Ela continuou: "Você me disse que seria muito bom ter um lugar que fosse seu, que você pudesse colocar suas coisas. Que você teria uma cama, se lembra?". Luis apertou sua mão, ela enxugou seus olhos. Desta vez, Luis chorou. A irmã sorriu para ela e disse "Me ensina a entender por que ele faz isso?" Ela the respondeu que poderiam conversar quantas vezes quisesse. Flávia e Luis teriam um longo caminho a ser percorrido ainda, mas já estão traçando os seus passos juntos...

Porém, passadas sete semanas após o inicio do atendimento deste novo ano algo do cenário antes descrito mudou radicalmente. Havia quatro semanas que Luis não comparecia às sessões. Apesar de sua psicóloga procurá-lo, não conseguia achar. O celular da irmã não respondia, o telefone da casa não atendia. Ela se perguntava onde estaria esse menino que não faltava às sessões sem aviso? Depois de quatro faltas, ela consegue falar no celular da irmã de Luis e sente nela o que já experimentara outras vezes: sobrevivência e luta no lugar de desistir diante do que ouvia... Uma história repetida ouvia-se do outro lado do celular, desta vez atendido: "Olha, estou devolvendo Luis para a minha tia. Não agüento mais, ele mente, o que ele diz para você não é o que ele é!" É perguntado à Flávia se ela não queria vir até a PUC para conversarem, já que há um mês tentava-se, em vão, achar Luis. A irmã responde que não: "Não adianta eu conversar, eu te ouvir, ele não muda. Eu

3 A favela onde Luis mora é violenta e o tráfico armado ali recruta adolescentes, sobretudo entre os mais miseráveis e abandonados. A combinação de famílias em dificuldades, repressão violenta e ausência de políticas publicas efetivas sela prematuramente o destino de muitos jovens e mesmo crianças. 
desisti, eu não quero mais, ele volta para a favela. Tô reunindo as coisas dele, tô levando tudo pra lá e não vou até você porque você não adianta nada, porque ele mente o tempo todo. Quer falar com ele? Ele está aqui." A psicóloga de Luis diz a ele quando este atende o celular: "Luis, por que você não veio? O que está acontecendo?" Silêncio, mais uma vez o silêncio foi a resposta dada por quem já perdera tantas vezes a esperança. Achávamos que agora ele estaria não mais somente começando a quebrar, estava quebrando de vez. A psicóloga arrisca e pergunta: "Você vem na próxima sessão? Eu estou te esperando, senti sua falta, você vem?" Ele responde que sim. A psicóloga desliga com a sensação de que deveria continuar a lutar, mesmo que não soubesse direito por onde, mas com certeza ela sabia por quem: por Luis e por ela.

"Sonhar um sonho impossível, lutar quando é fácil ceder, vencer um inimigo invencível"... foi a música lembrada por essa psicóloga ao desligar e ver pela janela, do outro lado da rua, outra criança, outro "capeta em forma de guri" esperando sua hora de ser atendido por ela. Sonhamos sonhos impossíveis, talvez por isso sejamos o que somos, talvez por isso sustentemos o insustentável, para que "capetas" possam vir, um dia, a ser crianças com direito a sorrir. Quando? Não sabemos, mas continuamos tentando que seja o mais breve possível.

Tratar de crianças como o Luis demanda uma clínica diferente. O ambiente deve algo ao que sofre: convém reconhecer a cobrança e pagar. Se o ambiente falta, é preciso oferecer-se. O vínculo está roto; a analista está ali para (re) construí-lo com ele. A confiança foi-se, não se pode falhar em ser essa segurança. Dar o não é possível, impedir o ato destrutivo é imperativo e estruturante, mas não é possível decepcionar.

É preciso acatar a demanda da criança e falar com ela, reforçando a palavra desses verdadeiros "rios sem discurso". Ás vezes é preciso falar por ele, reivindicando seu laço social e sua cidadania, os braços extensos da mãe, do pai e da família que ele perdera. É preciso, sim, ligar para o colégio, para o juiz, para o Conselho Tutelar, para o orelhão da favela, para os parentes e dizer que ele tem direito a respeito e dignidade. É preciso levá-lo ao ônibus e esperar seu aceno, é preciso ocupar o lugar de parente na formatura da escola, reafirmando seu direito à educação. É preciso fazer um bolo porque ele reivindica um aniversário, uma marca comemorativa de nascimento. Ele quer um bolo que seja só seu, do seu jeito, ou seja, quer uma singularidade - é preciso fazer.
É preciso reconhecer seu direito à convivência familiar e comunitária e recompor com ele uma possibilidade de família ${ }^{4}$. O analista precisa ser flexível e estender-se até oferecer suporte também para que a irmã da família recomposta possa compreender e acolher Luis sem desistir dele, sem deixar de ver o que de bom tem o menino mau.

A clínica psicológica muitas vezes está marcada pela dicotomia entre o social e o individual. Contudo, tal clínica não se sustenta com Luis e nem com outras crianças que reivindicam suas perdas pela via da destrutividade.

É necessário forjar uma clínica da criação e da experimentação de práticas que afinal são sempre sociais. É preciso instalar uma clínica do compromisso, da presença e da confiança - uma clínica que reafirma a vida humana daqueles que estão por um triz. É preciso se produzir uma prática clínica que afirme os direitos humanos para as vidas precárias, sua possibilidade incondicional de existência e seu acolhimento dentro da polis: uma comunidade para os desfiliados.

É uma clínica política, que indaga como uma sociedade baseada na desigualdade e atravessada pela violência e pela transgressão, pode ser um social e de que lugar ela chama as crianças dissonantes de antisociais. Se a sociedade ignora, desampara ou apenas providencia uma educação nazista para os anti-sociais, como aquela dada nas FEBENS e delegacias do Brasil (Zamora, 2005), a que social realmente nos referimos? Afinal, quem se importa de verdade?

\section{REFERÊNCIAS}

Maia, M. V. M. (2007). Rios sem discurso: reflexões sobre a agressividade da infância na contemporaneidade. São Paulo: Vetor.

Pelbart, P. P. (2003). Vida capital: ensaios de biopolítica. São Paulo: Iluminuras.

Safra, G. (2002). Memória e subjetivação. Memorandum, 2, 21-30. Disponível em: <http://www.fafich.ufmg.br/memorandum/ artigos02/safra02.htm.>. (Acesso em 20/08/2005).

Winnicott, D. W. (1987). Privação e delinqüiencia. São Paulo: Martins Fontes. (Original publicado em 1961).

Winnicott, D. W. (1963a) Comunicação e falta de comunicação levando ao estudo de certos opostos. Em D. W. Winnicott, $O$ ambiente e os processos de maturação: estudos sobre a teoria do desenvolvimento emocional (pp. 163-174). Porto Alegre: Artes médicas.

4 O parágrafo anterior e este parágrafo até a citação aludem, quase literalmente, aos direitos enumerados no Estatuto da Criança e do Adolescente. 
Winnicott, D. W. (1963b). Moral e educação. Em D. W. Winnicott, $O$ ambiente e os processos de maturação: estudos sobre a teoria do desenvolvimento emocional (pp. 88-98). Porto Alegre: Artes médicas.

Zamora, M. H. (2005). Para além das grades: elementos para a transformação do sistema sócio-educativo. Rio de Janeiro: PUC-Rio/São Paulo: Loyola.

Endereço para correspondência: Maria Vitória Campos Mamede Maia. Rua Visconde de Pirajá 303/sala 1103. Ipanema, CEP 22410-001, Rio de Janeiro-RJ. E-mail: mvitoriamaia@ig.com.br 